\title{
Impact of lowering ski binding settings on the outcome of the self-release test of ski bindings among female recreational skiers
}

This article was published in the following Dove Press journal: Open Access Journal of Sports Medicine

\author{
Markus Posch' \\ Martin Burtscher ${ }^{1}$ \\ Alois Schranz ${ }^{2}$ \\ Katja Tecklenburg ${ }^{2}$ \\ Kenneth Helle ${ }^{2}$ \\ Gerhard RuedI' \\ 'Department of Sport Science, \\ University of Innsbruck, Innsbruck, \\ Austria; ${ }^{2}$ Medalp Sportclinic, Imst, \\ Austria
}

Correspondence: Markus Posch Department of Sport Science, University of Innsbruck, Fürstenweg I85, 6020 Innsbruck, Austria

Tel +43 5I 2/507 45870

Fax +43 512/507 45999

Email Markus.Posch@uibk.ac.at
Background and purpose: The ability to successfully self-release the ski binding can prevent skiing-related injuries of the lower extremities. Failure of binding release associated with a knee injury is significantly higher among females compared to males. The International Standards Organization ISO 11088 standard for binding setting values allows a lowering by $15 \%$ upon request of the skier. Thus, the aim of this study was to evaluate the impact of lowered ski binding settings by $15 \%$ on the outcome of the self-release test among female recreational skiers.

Materials and methods: In this randomized single-blinded study, a cohort of 20 females (24.5 \pm 2.7 years) performed the self-release test in the laboratory thrice with each leg under two conditions: 1) with an actual ISO 11088 setting and 2) with a setting lowered by $15 \%$. For each attempt, torques calculated via the force plate were normalized to torques measured by a binding adjustment system (relative release torque, RRT).

Results: Among 240 trials in total, more females were significantly able to self-release their ski bindings with lowered binding settings when compared to their actual ISO settings (53\% vs $9 \%, p<0.001)$. Thirteen females $(65 \%)$ were able to release their bindings at least once with both legs with lowered binding settings compared to only three females (15\%) with their actual binding settings $(p<0.001)$. Mean RRT of all failure of binding release trials significantly differed between lowered and actual binding settings ( $58.6 \% \pm 22.2 \%$ vs $50.5 \% \pm 20.4 \%, p=0.003)$.

Conclusion: Four times more females were able to self-release their ski bindings at least once with both legs with a 15\% lowered binding setting compared to their normal ISO 11088 setting. The fact that the ISO standard accepts a lowering by $15 \%$ upon request of the skier could represent an important measure to prevent knee injuries, especially for female recreational skiers. Keywords: recreational skiing, prevention, knee injury, self-release test, lowered ski binding settings

\section{Introduction}

In recreational alpine skiing, the number of knee injuries, especially in females, continues to be the essential topic regarding injury prevention in alpine skiing. ${ }^{1,2}$ Accounting for about one-third instances, the knee is the most frequently injured body part. $^{3-5}$ Female recreational skiers, however, have twice the knee injury prevalence than that in male skiers, and the anterior cruciate ligament (ACL) injury risk is three times greater in female skiers. ${ }^{3,4}$ Furthermore, the large amount of failure of ski binding release at the moment of accident leading to a knee injury still seems to be a major problem among recreational alpine skiing. ${ }^{2}$ Knee-injured male recreational skiers reported a failure of binding release at the moment of accident in $55 \%-67 \%$ of 
cases compared to $74 \%-88 \%$ of cases reported by female skiers, ${ }^{2,6-9}$ despite the fact that sexes do not seem to differ with regard to neither the date of the last binding adjustment ${ }^{8}$ nor not correctly adjusted bindings. ${ }^{10}$ In the case of a failure of binding release at the moment of accident, the ski acts as a lever to bend or twist the leg, leading to a potential severe knee injury. ${ }^{11}$ Studies by Ekeland et al ${ }^{12}$ and Jørgensen et $\mathrm{al}^{13}$ showed that performing a daily self-release test of ski bindings, where skiers try to self-release their ski bindings by an inward twist of their foot and leg, ${ }^{14}$ can prevent skiing injuries of the lower extremity. Recently, Ruedl et $\mathrm{al}^{2}$ showed that among a cohort of about 500 male and female recreational skiers suffering from an ACL injury, binding release was independently associated with forward falling with rotation. This so-called forward twisting fall ${ }^{2}$ corresponds well with the self-release test of ski bindings. ${ }^{15}$ In a recent study among 30 physically active young adults with a self-reported advanced skiing skill level, Posch et a ${ }^{15}$ clearly showed that more females than males were unable to selfrelease their ski bindings within the self-release test $(80 \%$ vs $27 \%, p<0.01$ ) at least once with both legs, although all bindings were correctly adjusted according to the International Standards Organization (ISO) 11088 standard for binding setting values using an electronic test device and sexes did not differ regarding the relative isometric leg strength. In addition, the study by Posch et $\mathrm{al}^{15}$ also revealed a $20 \%$ difference of measured relative release torques (RRT) among trials of failure of binding release between the two sexes (males 50.6\% $020.1 \%$, females $40.9 \% \pm 20.2 \%, p=0.009$ ), characterizing a huge difference to the recommended ISO 11088 binding setting values. LaPorte et $\mathrm{al}^{16}$ already demonstrated that lowering binding release values by $15 \%$ among female recreational skiers could reduce knee injuries without an increase of inadvertent releases. Therefore, the question arises whether a lowering of the binding settings, especially for females by, eg, $15 \%$, would be relevant to enable them to self-release their ski binding and thereby probably decrease the risk of knee injuries. Currently, the ISO 11088 standard does not consider female sex, but already accepts a deviation of $15 \%$ between the measured release moment of a binding and the individual release moment determined according to the setting tables in ISO 8061. ${ }^{1}$ Pursuant to ISO 11088 standard point B.4, ski binding settings may also be lowered by the same magnitude among skiers who have satisfactory experience with lower settings without inadvertent releases or skiers who have a neutral skiing technique, defensive attitude, and a high degree of control. We hypothesized that female skiers would be able to self-release their ski bindings to a much higher extent when binding settings would actually be lowered by $15 \%$. Therefore, the aim of this study was to evaluate the impact of lowering the ski binding settings by $15 \%$ on the outcome of the self-release test among female recreational skiers.

\section{Materials and methods Subjects}

A total of 20 healthy females without any previous injury of the lower extremities agreed to volunteer for this study. Participants were physically active recreational skiers.

Informed written consent was obtained from all subjects prior to the start of the measurements. This study was performed in conformity with the ethical standards of the 2008 Declaration of Helsinki. Furthermore, the study was approved by the Institutional Review Board of the Department of Sport Science - University of Innsbruck.

\section{Study protocol}

After performing a standardized warming up program on a stationary cycle ergometer, the maximal isometric leg strength of both legs was tested by isometric leg strength test. Afterward, the self-release test of ski bindings was conducted in accordance with the methods described by Posch et al. ${ }^{15}$

\section{Study design}

Using a randomized single-blinded sudy design, subjects performed the self-release test three times with each leg under two conditions: 1) with actual binding settings according to the ISO 11088 standard and 2) with a 15\% lowered binding setting. In total, subjects performed a maximum of 12 trials ( 3 trials $\times 2$ binding settings $\times 2$ legs).

\section{Ski binding adjustment}

In this study, participants used their own skies and ski boots. Prior to the testing, skies and ski boots were taken to a ski rental shop (Patscheider, Serfaus, Austria) where a Wintersteiger Speedtronic adjustment system (Figure 1) was used to adjust the ski bindings in two different ways: 1) one ski with an actual ski binding setting according to the ISO 11088 standard and 2) the other ski with $15 \%$ lowered ski binding settings. Ski binding release values according to the ISO 11088 standard are determined using individual age, height, weight, skiing type, and sole length of ski boots. In addition, skiers must differentiate between skiing speed (slow to moderate vs fast), terrain (gentle to moderate vs steep), and skiing style (cautious vs aggressive) to classify themselves into one out of three skiing skill 
types. Afterward, both skies were marked and ski bindings were pasted over.

\section{Isometric leg strength test}

After the warm up, subjects performed three one-leg isometric leg extensions (Figure 2) on each leg in accordance with methods described by Raschner et al. ${ }^{17}$ The greater trochanter, lateral intercondylar notch, and lateral malleolus were used as landmarks to ensure that a knee angle of $100^{\circ}$ was achieved $\left(180^{\circ}=\right.$ fully extended knee). The calculated strength parameters are the highest recorded forces for each leg, and absolute leg force was relativized by body weight. ${ }^{17}$

\section{Self-release test}

As described by Posch et al, ${ }^{15}$ a wooden plate was fixed on a Kistler force plate. Furthermore, the ski was then fixed with metal bars on the wooden plate in a way that the participants were not able to move their skies neither in vertical nor in

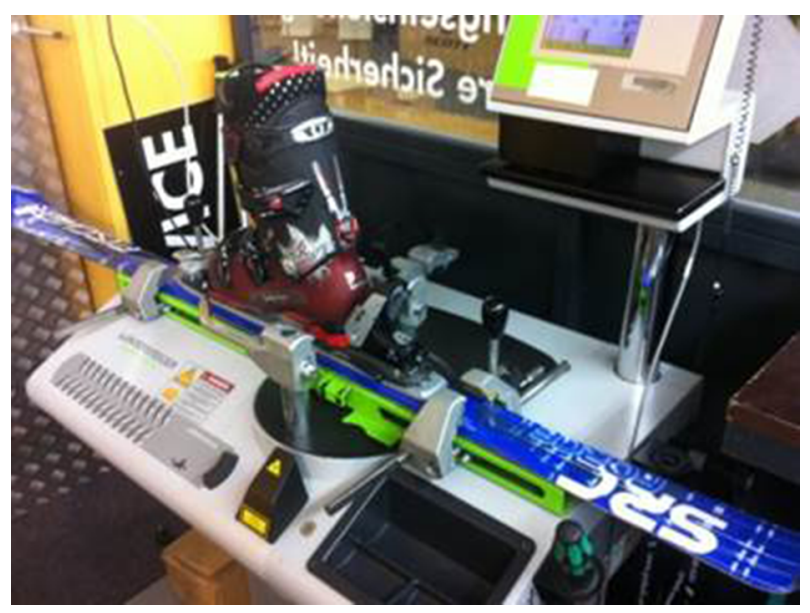

Figure I Wintersteiger Speedtronic - ski binding adjustment system.

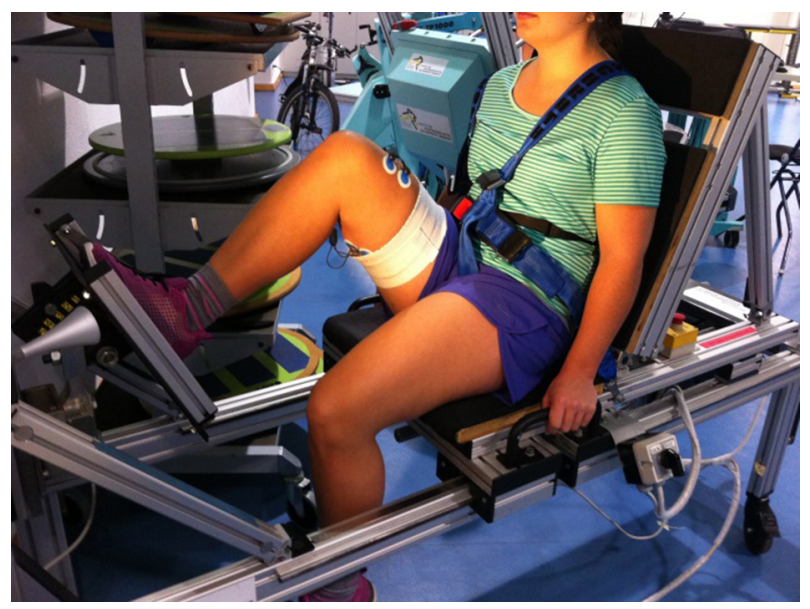

Figure 2 Isometric leg strength test. horizontal direction. Subjects received detailed instructions and got a demonstration on how to perform the self-release test by simultaneously avoiding a rotation of the hips and/ or valgus position of the knees. Furthermore, subjects were instructed not to touch the force plate with their opposing leg. The ground contact position of the standing leg was lower than that of the opposing leg. This difference in height makes it easier for subjects not to touch the force plate. To provide a ski-specific position, all participants were told to wear both ski boots and to use their own ski poles to stablize (Figure 3 ). Subjects were not allowed to practice the self-release movement before the testings. The task was to try to self-release the toe piece of the ski bindings by an inward twist of their foot and leg, but without an inward movement of their knee to prevent subjects from getting into a valgus position. ${ }^{15}$

For each attempt to release the ski binding, torques calculated via the force plate were relativized to torques determined by the Wintersteiger ski binding adjustment system (RRT) and represented by percentage values.

\section{Statistics}

Data are presented as means and absolute and relative frequencies. Differences in ski binding release frequencies

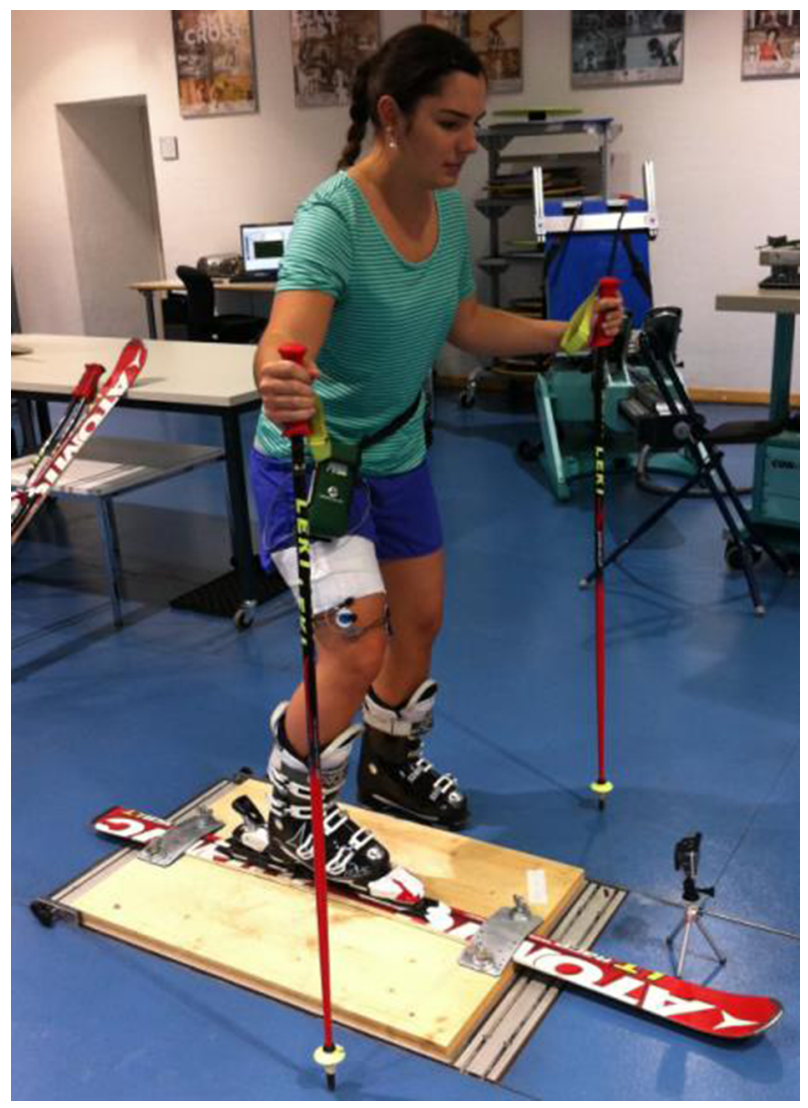

Figure 3 Self-release test of ski bindings on a Kistler force plate. 
were evaluated by McNemar tests. Depending on the results of the tests for normal distribution, changes in ski binding release torques and RRT between the two different ski binding settings were investigated either by dependent $t$-tests or Wilcoxon tests. SPSS 23.0 (IBM Corporation, Armonk, NY, USA) was used for the statistical analysis. All $p$-values were two-tailed, and values $<0.05$ were considered to indicate a statistical significance.

\section{Results}

Mean age, height, weight, body mass index, absolute isometric leg strength, and relative isometric leg strength of the whole sample size are listed in Table 1.

Within 120 trials for each ski binding setting ( 3 trials $\times$ 2 legs $\times 20$ subjects), more subjects were able to significantly self-release their ski bindings with lowered binding settings (Figure 4) compared to their actual ISO 11088 settings (53\% vs $9 \%, p<0.001)$. In total, 13 subjects $(65 \%)$ released their ski bindings with lowered binding settings at least once with both legs compared to only three females $(15 \%)$ with their actual ISO 11088 settings $(p<0.001)$.

Mean RRT of all 165 failure of binding release trials significantly differed between lowered and actual ISO 11088 ski binding settings $(58.6 \% \pm 22.2 \%$ vs $50.5 \% \pm 20.4 \%$, $p=0.003$ ).

Table I Baseline characteristics of participants

\begin{tabular}{ll}
\hline & Females $(\mathbf{n}=20)$ \\
\hline Age $($ years $)$ & $24.5 \pm 2.7$ \\
Height $(\mathrm{cm})$ & $166.8 \pm 5.1$ \\
Weight $(\mathrm{kg})$ & $63.1 \pm 4.3$ \\
Body mass index $\left(\mathrm{kg} / \mathrm{m}^{2}\right)$ & $22.7 \pm 1.4$ \\
Absolute isometric leg strength $(\mathrm{N})$ & $963.2 \pm 97.9$ \\
Relative isometric leg strength $(\mathrm{N} / \mathrm{kg})$ & $15.3 \pm 1.9$ \\
\hline
\end{tabular}

Note: Data are mean values \pm standard deviation.

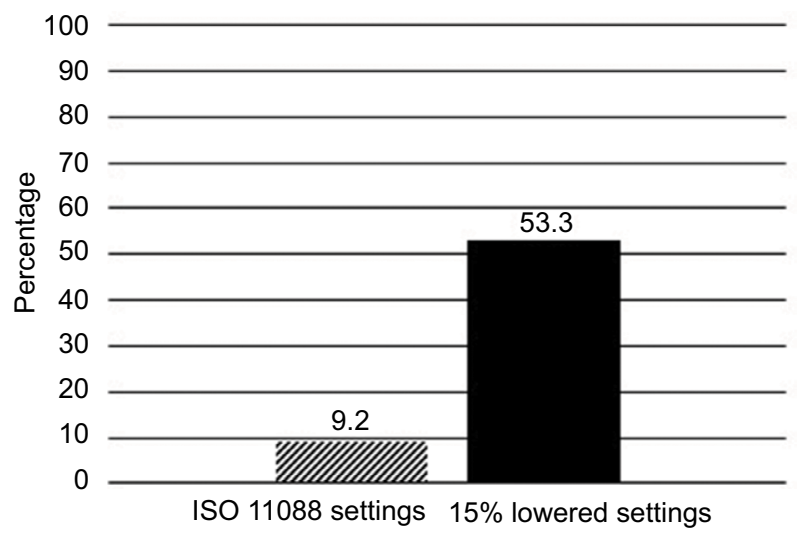

Figure 4 Relative frequencies (\%) of binding release among 120 trials in total for each ski binding setting within the self-release test.

\section{Discussion}

The aim of this study was to evaluate the impact of lowering ski binding settings by $15 \%$ on the outcome of the self-release test among female recreational skiers. The principal finding of this study was that among a total of 240 trials, four times more females were able to self-release their ski bindings with lowered binding settings compared to ski bindings with an actual ISO 11088 setting.

A failure of binding release during the self-release test was shown for $91 \%$ of trials, with an actual ISO 11088 setting compared to only $47 \%$ of trials with lowered binding settings. These findings among the proportion regarding failure of binding release are even higher compared to the results of an earlier study by Posch et a ${ }^{15}$ where $84 \%$ of female trials showed a failure of binding release of their ski bindings that were recently adjusted according to the ISO 11088 standard. This difference could be explained by the fact that in the earlier study by Posch et a ${ }^{15}$ more females were of an advanced skiing skill level compared to those in this study (73\% vs $45 \%$ ). Beginners might not be as familiar and experienced as advanced or expert skiers in self-releasing the toe piece of the ski binding by an inward twist of the foot and leg, although the maximum relative isometric leg strength was comparable among females of the two studies. ${ }^{15}$ Therefore, we assume that maximum relative isometric leg strength did not have a big influence on the outcome of the self-release test of ski bindings, and one could speculate that coordinative and technical aspects might play a more important role among females while performing the self-release test of ski bindings.

In this study, mean RRT among failure of binding release trials with lowered ski binding settings was about 14\% significantly higher compared to the RRT within trials with the actual ISO 11088 settings (58.6\% $\pm 22.2 \%$ vs $50.5 \% \pm 20.4 \%$, $p=0.003$ ), well reflecting the original difference of $15 \%$ between the two binding setting values. Both RRT parameters indicate a huge difference to the recommended ISO 11088 ski binding setting values. However, these huge differences occurred while performing the stationary self-release test in our laboratory and not in the field. Nevertheless, Scher and Mote $^{18}$ also showed that recommended release settings were significantly higher than the forces required to ski normally on varied terrain from hard to soft spring snow for 10-12 skiers. In addition, with regard to the lateral release setting at the toe, ten of the subjects skied within $67 \%$ of the current settings and could have lowered the setting by $33 \%$ without signaling for inadvertent release. ${ }^{18}$

Furthermore, the high amount of failure of binding release $(91 \%)$ in this study seems in line with results found among 
knee-injured recreational skiers where $74 \%-88 \%$ of female skiers reported of a failure of binding release at the moment of accident. ${ }^{2,6-8,15}$ Posch et a $1{ }^{15}$ associated the high amount of failure of binding release within the stationary self-release test of ski bindings with the findings observed by LaPorte et $\mathrm{al}^{7}$ who showed that $44 \%$ of lower leg injuries occurred at low speed or in a stationary standing position. The particular problem about failure of binding release is the fact that the long lever arms of the ski create substantial magnitudes of torque about the knee joint and the ski acts as a lever arm for a longer period of time than it would if the binding is released. ${ }^{11}$ For these reasons, a failure of binding release can lead to a severe knee injury and is still the central issue regarding injury prevention in alpine skiing. ${ }^{1}$

In this study, 13 out of 20 females (65\%) were able to self-release their bindings with $15 \%$ lowered settings at least once with both legs compared to the study by Posch et a ${ }^{15}$ where 11 out of 15 males (73\%) with an actual ISO 11088 binding setting self-released their bindings at least once with both legs. Besides that, $53 \%$ of all trials with $15 \%$ lowered ski binding settings among female participants of the underlying study showed a binding release, whereas $46 \%$ of all trials with an actual binding setting among male participants of the previous study by Posch et a $1{ }^{15}$ led to a self-release.

To sum up, reducing binding release values by $15 \%$ among females can lead to comparable or even better results compared to males with normal ISO 11088 binding settings of the study by Posch et al. ${ }^{15}$ Generally, lowering ski binding release moments by $15 \%$ had a huge impact on the outcome of the self-release test among female recreational skiers. Reduced binding setting values among females should be seriously taken in consideration when discussing effective measures to prevent female knee injuries in recreational alpine skiing especially at low speed. In a case-control study, LaPorte et $\mathrm{al}^{16}$ already reported that lower binding release values in female skiers set $15 \%$ lower than those recommended by the ISO 11088 standard would clearly reduce knee injuries in these persons without an increase in injuries from inadvertent binding release. However, these findings mean an association and not explicit cause-and-effect relationship because at the same time Ettlinger et al ${ }^{19}$ showed a decrease in ACL injury risk without reducing binding settings, which might be partly due to the introduction of the short and shaped carving skis. ${ }^{8}$

Interestingly, the ISO 11088 standard already accepts and allows a deviation of $15 \%$ between the measured release moments of a binding and the individual release moments determined according to the setting tables in ISO 8061, and ski binding settings may also be lowered by the same magnitude upon request of the skier. ${ }^{1}$ Unfortunately, this fact is generally unknown in the overall skier population but could represent an important potential preventive measure, as our tests showed that significantly more female recreational skiers were able to self-release their ski bindings with lowered binding settings compared to their actual ISO 11088 settings. Furthermore, it was proven that lowering ski binding settings by $15 \%$ would not lead to an increased amount of inadvertent releases. ${ }^{16,18}$ Therefore, it is needed to make the accepted deviation of $15 \%$ within the ISO 11088 standard for binding release values more popular.

One limitation of this study is the transferability of the self-release test from a laboratory setting into field settings. This study was carried out in a controlled laboratory environment under standardized conditions, and it is possible that failure of binding release and RRT might be different in field conditions. However, Scher and Mote ${ }^{18}$ convincingly demonstrated in the field that the recommended release settings were significantly higher than the applied forces during usual skiing in variable terrains, underpinning the meaningfulness of self-release testing.

\section{Conclusion}

Significantly more females were able to self-release their ski bindings with lowered binding settings compared to their actual ISO 11088 settings. In addition, fourfold more females were able to self-release their ski bindings at least once with both legs with $15 \%$ lowered binding settings compared to their actual ISO 11088 settings. The fact that according to the ISO standard ski bindings can be lowered by $15 \%$ upon request of the skier could represent an important measure to prevent knee injuries, especially for female recreational skiers.

\section{Acknowledgments}

The abstract of this paper was presented at the 22nd conference of the International Society for Skiing Safety (ISSS) at Innsbruck/Austria, April 17th-22nd, 2017.

The authors gratefully acknowledge support for this study from the Tiroler Wissenschaftsfond (TWF). The study sponsor was not involved in study design, collection, analysis, and interpretation of data or in the writing of the manuscript.

Furthermore, the authors are deeply grateful to Franz Patscheider for providing the Wintersteiger Speedtronic adjustment system in his ski rental shop.

The subject shown in the images has provided written informed consent for all images to be published. 


\section{Disclosure}

The authors report no conflicts of interest in this work.

\section{References}

1. Senner V, Michel FI, Lehner S, Brügger O. Technical possibilities for optimizing the ski-binding-boot functional unit to reduce knee injuries in recreational alpine skiing. Sports Eng. 2013;16:211-228.

2. Ruedl G, Helle K, Tecklenburg K, Schranz A, Fink C, Burtscher M. Factors associated with self-reported failure of binding release among ACL injured male and female recreational skiers: a catalyst to change ISO binding standards? Br J Sports Med. 2016;50:37-40.

3. Burtscher M, Gatterer H, Flatz N, et al. Effects of modern ski equipment on the overall injury rate and the pattern of injury location in alpine skiing. Clin J Sport Med. 2008;18(4):355-357.

4. Ekeland A, Rodven A. Skiing and boarding injuries on Norwegian slopes during two winter seasons. J ASTM Int. 2011;7(4):1-8.

5. Ruedl G, Philippe M, Sommersacher R, Dünnwald T, Kopp M, Burtscher M. Aktuelles unfallgeschehen auf Österreichischen skipisten [Current incidence of accidents on Austrian ski slopes]. Sportverletz Sportschaden. 2014;28(4):183-187.

6. Greenwald RM, Toelcke T. Gender differences in alpine skiing injuries: a profile of the knee-injured skier. In: Johnson RJ, Mote CD, Ekeland A, editors. Skiing Trauma and Safety. Vol 11. West Conshohocken, PA: ASTM; 1997:111-121.

7. LaPorte JD, Binet MH, Fenet N, Constans D, Joubert P. Ski bindings and lower leg injuries, a case control study in Flaine, 2006. In: Johnson RJ, Shealy JE, Langran M, editors. Skiing Trauma and Safety. Vol 17. West Conshohocken, PA: ASTM; 2009:77-88.

8. Ruedl G, Webhofer M, Linortner I, et al. ACL injury mechanisms and related factors in male and female carving skiers: a retrospective study. Int J Sports Med. 2011;32(10):801-806.

9. Posch M, Ruedl G, Tecklenburg K, Helle K, Schranz A, Burtscher M. Are there sex differences regarding ski length to height ratio, ski length to weight ratio, sidecut radius and ski boot sole abrasion among ACL injured male and female skiers? Sportverl Sportschaden. 2017;31(2): 87-92. German.
10. Ruedl G, Sommersacher R, Woldrich T, Kopp M, Nachbauer W, Burtscher M. Mean speed of winter sport participants depending on various factors. Sportverletz Sportschaden. 2010;24(3): 150-153.

11. Natri A, Beynnon BD, Ettlinger CF, Johnson RJ, Shealy JE. Alpine ski bindings and injuries. Current findings. Sports Med. 1999;28(1): $35-48$.

12. Ekeland A, Holtmoen A, Lystad H. Lower extremity equipmentrelated injuries in alpine recreational skiers. Am J Sports Med. 1993;21(2):201-205.

13. Jørgensen U, Fredensborg T, Haraszuk JP, Crone KL. Reduction of injuries in downhill skiing by use of an instructional ski-video: a prospective randomised intervention study. Knee Surg Sports Traumatol Arthrosc. 1998;6(3):194-200.

14. Werner S, Willis K. Self-release of ski-binding. Int $J$ Sports Med. 2002;23(07):530-535.

15. Posch M, Ruedl G, Eberle R, Burtscher M. Self-release of ski bindings: a sex comparison. In: Scher IS, Greenwald RM, Petrone N, editors. Snow Sports Trauma and Safety. Vol 21. Cham, Switzerland: Springer; 2017:109-117.

16. LaPorte JD, Binet MH, Fenet N, Constans D. Ski bindings and lower leg injuries: a two year case-control study in Avoriaz. Abstracts of the sixteenth international symposium on ski trauma and skiing safety, Arai Mountain, Niigata, Japan, 17-23, April 2005. Knee Surg Sports Traumatol Arthrosc. 2006;14:100-101.

17. Raschner C, Platzer HP, Patterson C, Werner I, Huber R, Hildebrandt C. The relationship between ACL injuries and physical fitness in young competitive ski racers: a 10-year longitudinal study. Br J Sports Med. 2012;46:1065-1071.

18. Scher IS, Mote CD. Comparison of needed and recommended retention settings for snow skiing. In: Johnson R, editor. Skiing Trauma and Safety. Vol 12. West Conshohocken, PA: ASTM; 1999:107-119.

19. Ettlinger CF, Johnson RJ, Shealy JE. Functional and release characteristics of alpine ski equipment. Abstracts of the sixteenth international symposium on ski trauma and skiing safety, Arai Mountain, Niigata, Japan, 17-23 April 2005. Knee Surg Sports Traumatol Arthrosc. 2006;14:97-104.
Open Access Journal of Sports Medicine

\section{Publish your work in this journal}

The Open Access Journal of Sports Medicine is an international, peer-reviewed, open access journal publishing original research, reports, reviews and commentaries on all areas of sports medicine. The journal is included on PubMed. The manuscript management system is completely online and includes a very quick and fair

\section{Dovepress}

peer-review system. Visit http://www.dovepress.com/testimonials.php to read real quotes from published authors. 